\title{
On a Cross-Cultural Memescape: Switzerland through Nation Memes from within and from the Outside
}

\author{
Marta Dynel \\ Associate Professor, Faculty of Philology, University of Łódź, Łódź, Poland \\ marta.dynel@yahoo.com \\ Thomas C. Messerli \\ Postdoctoral Research and Teaching Fellow, Department of English, \\ Universität Basel, Basel, Switzerland \\ thomas.messerli@unibas.ch
}

\begin{abstract}
This paper offers a cross-cultural contrastive study of what we term 'nation memes'. These are humorous internet memes which refer to a particular country/nation. Our analysis of cultural scripts in memes related to Switzerland is based on a tripartite corpus of digital items shared by Polish, Swiss and international communities. By adopting a grounded-theory approach, we examine the prevalent scripts that represent the Swiss and Switzerland from each of the three perspectives. The results of our qualitative study indicate that Swiss memes are based on experiential knowledge of life in Switzerland, as well as a few stereotypes adopted by the Swiss about their own nation. The Polish subcorpus addresses Switzerland from an outsider perspective by invoking well-known cultural scripts, similar to those on international websites, on which Polish users sometimes scavenge. However, the Polish memescape uses scripts about Switzerland to address problems and scripts specific to Poland. Importantly, nation memes do not necessarily involve humorous disparagement, i.e. they do not always take Switzerland/the Swiss to be the target at which to poke fun when building humorous superiority. Moreover, by referring to their own national vices, the Swiss and Poles sometimes use cultural scripts as the basis for self-deprecating humour.
\end{abstract}




\section{Keywords}

cultural scripts - nation memes - insider/outsider perspective - humorous (self) disparagement - (inter)cultural memescape

\section{Introduction}

The last two decades have seen a massive increase in the number of studies devoted to online humour across disciplines. This is a consequence of the development of Web 2.0 and the emergence of participatory culture (Jenkins et al., 2009), and hence the ever-increasing wealth of user-generated humorous data. These data include both traditional forms of humour, such as verbal jokes circulated on the Internet rather than being passed on orally or in print (e.g. Yus, 2017; Hirsch, 2017), and multimodal forms facilitated by, and specific to, online communication (e.g. Dynel and Poppi, 2019; Vásquez, 2019; Zhang and Cassany, 2019), which is epitomised by humorous memes.

The point of departure for the current research project is an assumption that memes can provide insight into how a nation and its culture are perceived by other nations/cultures, as well as how a nation portrays itself. Humour, in its various forms, is known to reflect various cultural scripts, i.e. "representations of cultural norms which are widely held in a given society and are reflected in language" (Wierzbicka, 2014: 339), or rather in communication in general. Following Kecskes (2014), culture should be understood to be a set of shared not only norms and beliefs but also behaviours and artefacts, as represented in socially constructed mental models (van Dijk, 2008) encoded in the multimodal text-image ensembles that we examine in this study (cf. de Jongste, 2016 for a different application of mental models in humour research).

While studies abound on traditional verbal jokes and their underlying cultural scripts, including stereotypes (e.g. Davies, 1990, 2009; Kuipers, 2000; Popescu, 2011), there has been hardly any consistent research on memes in this respect. This study aims to fill this gap by addressing what we have termed 'nation memes'. We carry out a contrastive study of memes, by focusing on the case of one country as viewed from the outside and from within. We deploy a tripartite corpus of humorous memes that refer to Switzerland, a country which has not been investigated as the target of jokes (but see Davies, 2005), in three different cultural contexts: Polish websites (with Poles being an example of an outsider group); the Instagram account swissmeme (memes that are generally created by and for Swiss residents, i.e. the insider group); and an international meme site, where the producers and receivers of humour are diverse in 
terms of their nationalities and geographical locations, representing an intercultural perspective. By adopting a grounded-theory approach, we address the memes with a view to finding representations of Switzerland, and thus the cultural scripts of Switzerland that operate on the intracultural or intercultural memescape.

We situate our analysis of nation memes in the context of previous studies of memes and humour (Section 2). We then outline our data collection method and the methodological steps of our corpus-based qualitative analysis (Section 3), before we present our findings in topical clusters (Section 4), and thus highlighting the overarching meme themes on the Polish (Section 4.1), Swiss (Section 4.2) and international (Section 4.3) humour hubs. Finally, we summarise and discuss our results, and we examine the ways in which we can further our understanding of the role played by memes in the negotiation of cultural scripts about nations in different cultural spaces (Section 5 ).

\section{Memes and Ethnic Humour}

Internet memes, or simply memes, are - without doubt - the most extensively discussed form of what is known as 'Internet humour', 'online humour' or 'digital humour'. Even though Internet memes are generally regarded to be a form of humour by humour scholars, it should be emphasised that memes do not need to have humorous potential, as many studies outside the field of humour research have shown (see Dynel, 2016). This is also in accordance with Dawkins' (1976) coinage of 'meme', namely a cultural unit that infects individual minds and proliferates through replication. Here, in line with common practice, 'meme' is used as shorthand for a humorous Internet meme, which may encompass various textual, visual and multimodal forms (Knobel and Lankshear, 2007; Shifman, 2013; Huntington, 2015). Overall, 'memes' are defined as humorous, multimodal, user-generated "digital items sharing common characteristics of content, form, and/or stance", which are "created with awareness of each other" and "circulated, imitated, and/or transformed via the Internet by many users" (Shifman, 2013: 41; cf. Huntington, 2015: 78; Gal et al., 2016: 1700). In practice, both in popular parlance and in academic discourse, the label 'meme' is used in reference to any humorous multi-modal digital item generated by an ordinary Internet user, even if not all of these three conditions are met.

The majority of meme studies deploy English-speaking data, with English being used as the lingua franca of the Internet, and often address the universal workings and functions of memes as digital items that traverse nations 
and cultures (e.g. Wiggins and Bowers, 2015). However, there are indeed some studies that focus on specific socio-political problems, such as US politics (e.g. Milner, 2013, 2016; Huntington, 2015; Ross and Rivers, 2017). Some studies, based on consistently collated data, shed light on non-Anglo-centric national memetic trends, by examining the memes of one nation, such as Israeli memes (Sebba-Elran and Milo, 2016) or Omani memes (Al Zidjaly, 2017), or by offering a cross-cultural comparison of meme templates (Nissenbaum and Shifman, 2018). However, there appears to be a dearth of research on memes as carriers or mirrors of cultural scripts about nations.

The traditional form of canned jokes (passed on orally, compiled in joke books, or - more recently - circulated on the Internet) has been extensively discussed in the context of underlying ethnic scripts, whereby selected ethnic or national groups are disparaged on the basis of features attributed to them (e.g. Schutz, 1989; Davies, 1990, 2009; Apte, 1987; Weaver, 2011). Very often, nations and other ethnic groups function as arbitrarily selected targets/butts subject to universal dichotomous evaluations, such as stupidity versus canniness (e.g. Davies, 199o; Boxman-Shabtai and Shifman, 2015). As Takovski (2018: 61) rightly observes, these non-specific features "are not constitutive of the ethnic identity of the ridiculed group as they do not relate to what research on ethnicity has termed as identity markers, referring to the ethnically idiosyncratic, distinguishing qualities such as kingship, language, religion, customs, ancestry, and shared history, which define the contents and the boundaries of ethnic groups". On the other hand, ethnic humour may ridicule characteristics inherent to a given ethnic social group, by poking fun at "different traits of a group and/or its members thanks to their social, political, cultural, religious and economic background" (Apte, 1985: 115).

Resembling canned jokes, memes, seen as verbal-visual or - more generally - multimodal jokes (Dynel, 2016; Messerli and Yu, 2018; Yus, 2019), can reflect existing cultural scripts and stereotypes (cf. Boxman-Shabtai and Shifman, 2015), not just those related to ethnicity or other social groups per se. Therefore, not all humour relating to a nation or culture qualifies as ethnic humour. Jokes and memes can address various socio-cultural facts and phenomena. Hence, we propose the concept of nation memes, which encompasses not only digital ethnic humour but also digital humour about peoples, sociocultural and historical facts and phenomena, which meme creators consider to be typical of a particular nation. It is evident that cultural scripts will vary according to the meme creators' perspectives.

While memes are sometimes regarded as globalisation vehicles (see Shifman et al., 2014), they can also involve localisation, whereby local cultures affect memetic content (e.g. Shifman, 2013). As Jiang and Vásquez (2019: forthcoming) 
accurately state, "focusing on localization processes can be extremely useful in shedding light on digital discursive practices, as well as ideas, values and issues specific to that particular culture." Specifically, by studying memes published on different local websites, the various conceptions of Switzerland from a number of vantage points can be compared.

\section{$3 \quad$ Methodology}

This study of cross-cultural memes was determined by the nationalities of the two co-authors, and hence their access to the relevant data sources. The original goal was to examine the Polish perception of Switzerland and the Swiss perception of Poland, but this idea was abandoned because of a scarcity of relevant material on Swiss websites, which might indicate that Poland-related cultural scripts are not particularly important to the Swiss (cf. Polack jokes in the USA or EU, see e.g. Dundes, 1971; Davies, 199o; Weaver and Ozieranski, 2015). Therefore, the data used for the current study are humorous memes about Switzerland which were found on Polish and Swiss websites by the two authors, with each author searching his/her own country's websites. As an additional point of reference and source of comparison, international memes were also collected. The corpus comprising the three subcorpora was built in November 2019 .

Polish memes about Switzerland were sought on the most popular (according to website traffic values) entertainment websites in Poland, which feature primarily (but not exclusively) humour of various types: demotywatory.pl, kwejk.pl, memy.pl and memy.jeja.pl. All searches were based on the Szwajcar* search term, which yielded data pertinent to Szwajcaria (Switzerland), Szwajcar (ka) (a Swiss man or woman), Szwajcarzy (the Swiss) and Szwajcarski/ $a / e$ etc. (Swiss). After deleting reposts of the same items, a substantial corpus of memes $(n=174)$ was built.

A search for Swiss memes about Switzerland was conducted on the Instagram account swissmeme, on which memes are posted in Swiss German. At the time of collection, swissmeme had more than 800,ooo followers - a staggering number given that there are only 6 million Swiss German speakers. Out of the 4479 memes on swissmeme, which are mainly humorous and relate, in some way, to life in Switzerland, we included only those memes that explicitly referred to Switzerland $(n=85)$, by including either the tag Schwiiz (Switzerland) or the Swiss flag as an unambiguous pictorial reference to Switzerland.

Finally, the international part of the corpus was collected on me.me, where the keywords Schweiz, Swiss and Switzerland were used. This resulted in the 
collection of a smaller number of memes $(n=64)$ that served the contextualisation and interpretation of the findings in the two main subcorpora.

During the compilation of each subcorpus, all non-humorous memes in the feed were disregarded. The determining criterion was the presence of some form of incongruity, which is the hallmark of all humour (see e.g. Martin, 2007; Forabosco, 2008; Martin and Ford, 2018). Incongruity manifests itself as a structural property of creative stimuli or a cognitive clash based on the surprise effect (see Dynel, 2013 and references therein).

The tripartite corpus of humorous memes thus obtained was open-coded through an iterative process and through a grounded-theory approach, to obtain the primary topics and scripts about the culture and social reality of Switzerland and its people, as perceived by the users of the selected websites. While presumably only Poles use websites in Polish, the Swiss Instagram account swissmeme represents a Swiss perspective. The creators of the international memes are less definable, but the memes themselves can provide further insight into the positions they have adopted. Each of the categories, i.e. cultural scripts, is represented in the respective subcorpus by a minimum of 5 items, but in practice some of the categories contain more than 20 memes.

Analysis

The analysis presents the most salient cultural scripts found within each subcorpus. The categories are discussed with reference to selected representative examples. In the following, we will present categories of Polish (Section 4.1), Swiss (Section 4.2) and international (Section 4.3) memes.

\subsection{Polish Memes about Switzerland}

This section details six categories of memes/cultural scripts which were found on the Polish humour hubs.

\subsubsection{Neutrality and Profit-Making during WWI and WWII}

The most prevalent cultural script found in the Polish data is that of Switzerland's non-engagement in combat and profit-making during wwI and WwiI (Figure 1). The memes offer multimodal metaphorical representations (cf. Forceville, 2008; Forceville and Urios-Aparisi, 2009) of this historical schema, and these metaphors display humorous potential (Tsakona, 2009; Dynel, 2009). One presents two boys fighting, while a girl sits at a table sipping a drink through a straw, totally unaffected by the events unfolding around her. The metaphor is established by labelling the boys 'Allies' and 'Nazis', and the 


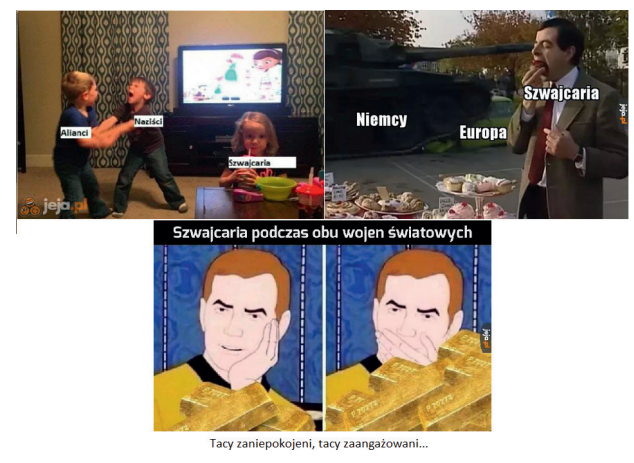

FIGURE 1

Top left: Allies / Nazis / Switzerland Top right: Germany / Europe /

Switzerland

Bottom: Switzerland during both World Wars // So worried, so engaged ...

girl 'Switzerland'. Similarly, the second meme, which is based on intertextuality (e.g. Kristeva, 1980; Norrick, 1989), shows a modified still from the $\mathrm{Mr}$ Bean TV series: a military tank (labelled 'Germany') demolishes a small car representing Europe, while Rowan Atkinson in the role of Mr Bean (symbolising Switzerland) is enjoying a cake. Thirdly, another intertextuality-based meme entitled 'Switzerland during both World Wars' presents two drawings of the cartoon version of James T. Kirk (from Star Trek: The Animated Series). In the left-hand drawing, he supports his head on his hand and looks worried about a small pile of gold bars and then, in the right-hand drawing, he covers his mouth and appears shocked by a large pile of gold bars. This item bears an ironic (cf. Dynel, 2018 and references therein) caption 'So worried, so engaged', thus implicitly criticising the Swiss for their lack of worry or engagement during WWI and WWII while, at the same time, accumulating wealth.

As we will discuss later (see Section 4.3.1), this script can also be found on international humour hubs, sometimes using the very same memes, albeit in English. Hence, the Polish examples display a characteristic that could be considered a violation of the presupposed norm underlying meme formation, which should be a creative process, albeit based on repetition, reuse and recontextualisation. At least 19 of the digital items found on the Polish 'humour hubs' are evidently translations and reposts of English-language memes, which can be found by searching Google images (Figure 2). It is rather unlikely that memes encountered on a Polish website would be translated into English and posted on an international one for a much broader community to view. The direction of translation is - at least in some cases - indicated by publication dates, ${ }^{1}$ as well as some metapragmatic comments in which users communicate their criticism of translated memes for going against implicit

1 For instance: https://me.me/i/switzerland-during-wwii-just-hope-both-teams-have-fun -neutral-1b223201283045eeg16dada6fd3a79ob.

https://demotywatory.pl/4930139/Szwajcaria-w-czasie-II-wojny-swiatowej 


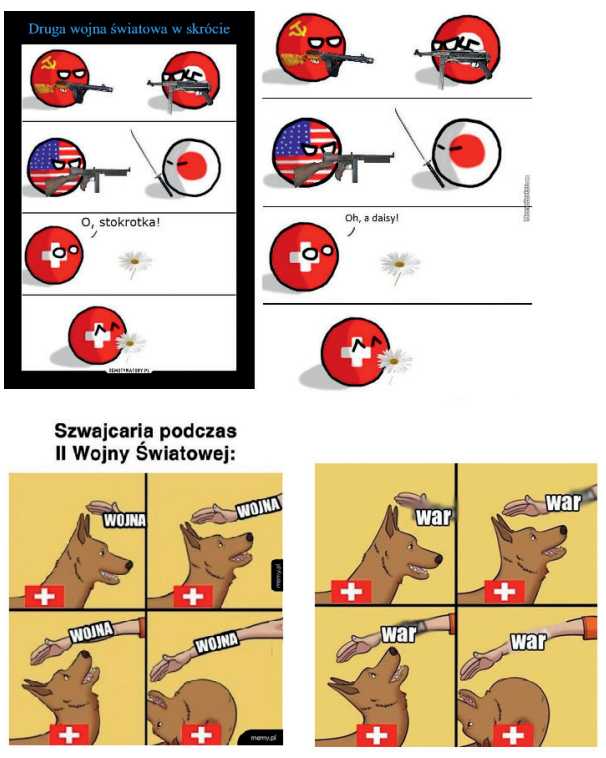

FIGURE 2

Top left: World War II in a nutshell // Oh, a daisy!

Bottom left: Switzerland during World War II: // war

guidelines of creativity. Users that post memes on Polish humour websites are not necessarily trying to earn kudos for their creativity, which appears to be an unwritten policy for the majority of online humour (cf. Dynel and Poppi, 2019, 2020a). Those engaged in translating and reposting could be considered to adopt a 'scavenger' approach to memetic production, without being particularly creative themselves, their sole contribution being only the changing of the codes. They appear to be more concerned with sharing something they consider to be funny with the Polish audience, on the assumption that some Poles might not be competent at English or follow international humour hubs.

The two Polish memes in Figure 2, entitled 'World War II in a nutshell' (top) and 'Switzerland during World War II' (bottom), appear to be direct translations of English-based memes (on the right). The first meme based on the country balls format depicts four countries at war while Switzerland becomes distracted by a flower. The second meme features a dog, metaphorically representing Switzerland, which adroitly avoids war.

\subsubsection{Affluence and Financial Heaven}

The second recurrent type of nation meme relating to Switzerland concerns the country's perceived affluence and the financial heaven it offers its people in many spheres of life. These attributes are juxtaposed with the financial conditions experienced in Poland in an either explicit or implicit act of downward social comparison. Whilst presenting what the users consider to be truthful 


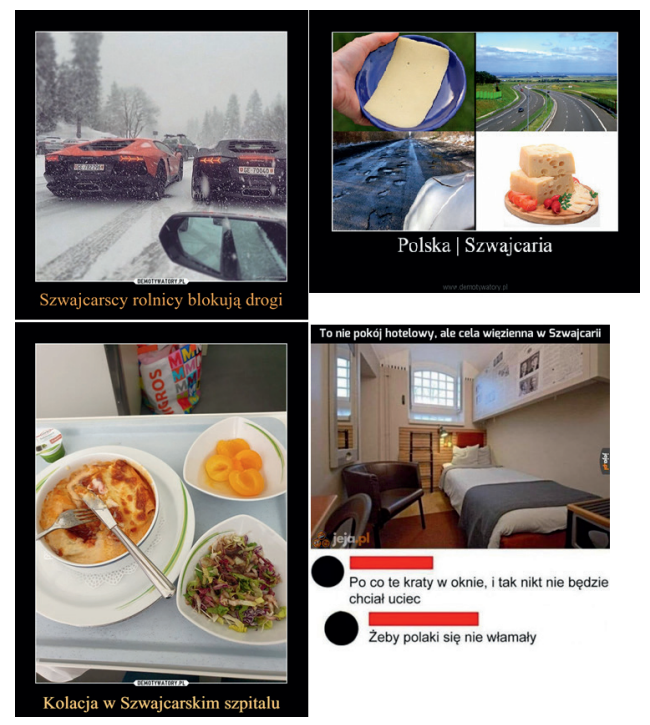

FIGURE 3

Top left: Swiss farmers blocking the road.

Top right: Poland | Switzerland Bottom left: Supper in a Swiss hospital Bottom right: This is not a hotel room but a prison cell in Switzerland // Why these bars on the window, no one will want to escape anyway // So that Polacks do not break in

meanings (Dynel, 2018) about the two countries, the memes are evidently based on exaggeration, if not absurdity, as shown by the photograph of two sports cars humorously attributed to Swiss farmers, whereby the meme tacitly alludes to repeated protests by Polish farmers who struggle to earn a living. In contrast, the second example is altogether more realistic. It is based on a chiastic juxtaposition of Polish cheese and streets full of holes with Swiss cheese and high-quality streets, which is indicative of each country's level of affluence. The remaining two memes visually represent user-reported facts about Switzerland, which are corroborated with visual evidence: the tasty-looking supper in a Swiss hospital (which is in marked contrast with the proverbially simple and rather unpleasant food in Polish hospitals); and the excellent conditions in a Swiss prison cell which, as stated in the caption, looks like a hotel room. In addition, the comments posted below the original meme add another layer of meaning: in addition to addressing Switzerland, this digital item also targets Poles, by presenting them as a nation that could potentially break into a luxurious prison in order to live there or to steal the furniture.

The affluence of the Swiss is manifest in the context of a downward comparison with not only Poland but also other countries, such as Germany. In the country-ball meme in Figure 4, the ball representing Germany, a country perceived as rich in Poland, as well as in other countries, wishes to deposit what seems to be a huge amount of money, which is treated as a symptom of poverty by the Swiss country ball. Whilst the Swiss are portrayed as an open-minded nation, their bar for the affluence vs. poverty distinction is placed rather high. 


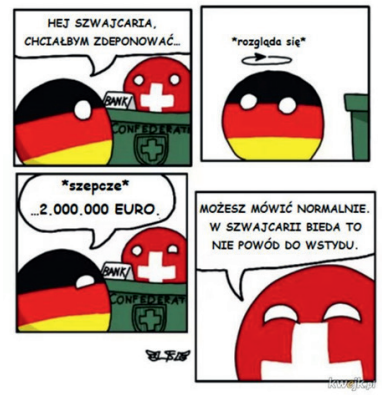

FIGURE 4

Hi Switzerland, I would like to deposit ... // *looking around* // *whispers*... 2. ooo.ooo Euro. // You can speak normally. In Switzerland, poverty is no shame

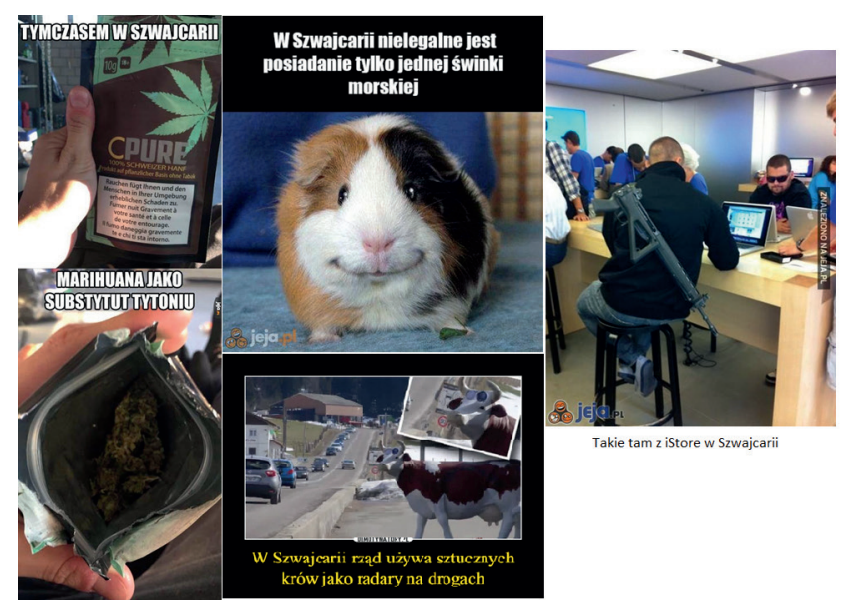

FIGURE 5 Left: Meanwhile in Switzerland // Marijuana as a tobacco substitute.

Centre top: In Switzerland it is illegal to have one guinea pig only.

Centre bottom: In Switzerland, the government uses fake cows as radars on the roads.

Right: Something from an iStore in Switzerland

\subsubsection{Unusual Legal Acts}

The category exemplified in Figure 5 encompasses memes that report what appear to be local legal acts or their consequences, either regarded as being rather unusual. The memes are anchored in verbal statements and/or visual messages that give rise to humorous cognitive incongruity which is dependent on the simple surprise effect (see Forabosco, 1992, 2008; Martin, 2007) that, in Switzerland, it is possible to buy marijuana, people can casually carry guns, owning only one guinea pig is not allowed and road radars are installed in fake cows. In addition, the first meme either portrays the author's envy of the Swiss 


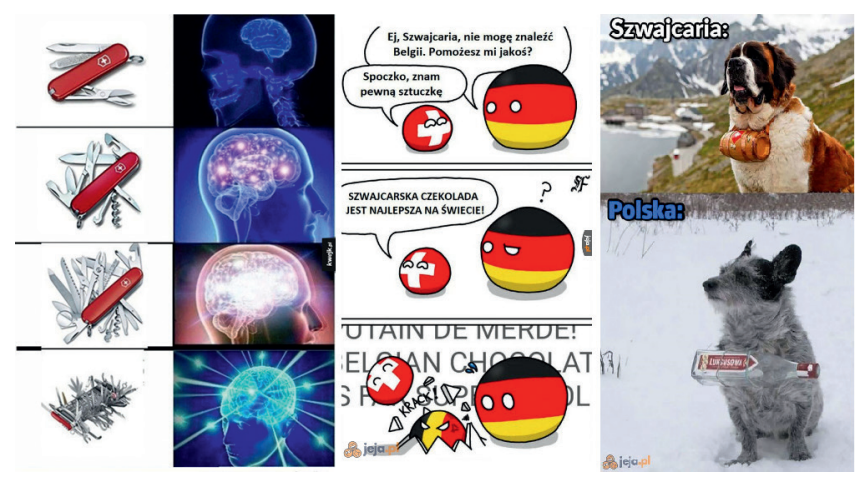

FIGURE 6 Centre: Hey, Switzerland, I can't find Belgium. Can you help me somehow? // Sure, I know a trick. // SWISS CHOCOLATE IS THE BEST IN THE WORLD!

law that (to an extent) decriminalises cannabis or appreciates the fact that the law can be explicitly circumvented (some cannabis-based products are not illegal and the leaf image can be freely used).

\subsubsection{Symbols}

As the examples in Figure 6 illustrate, some Polish memes humorously invoke but do not necessarily make fun of - what may be considered to be symbols of Switzerland, namely the Swiss army knife, Swiss chocolate and the St. Bernard dog. Swiss army knives of varying complexity are jocularly associated with different levels of brain activity. On the other hand, the country balls meme alludes to the high quality of Swiss chocolate, which is presented in competition with Belgian chocolate. In the third item, a Swiss rescue dog in the Western Alps with a small barrel of brandy is juxtaposed with a Polish mongrel carrying a bottle of popular cheap vodka, which pokes fun at Poland in an act of self-deprecation.

\subsubsection{Football Defeat}

The Polish websites still feature many memes that refer to the Euro 2016 match in which Poland defeated Switzerland on penalties and qualified for the quarter-finals for the first time, an achievement in which Poles took great pride. The item on the left is a picture of a shop window with a witty rhyming slogan (note that the colours that are used visually represent the Polish flag, which is also included) that expresses superiority over the Swiss. This slogan must have been observed just after the Poland-Switzerland match. The second meme shows two babies, one laughing, the other crying, who metaphorically represent Poland and Switzerland respectively. While referring to the 


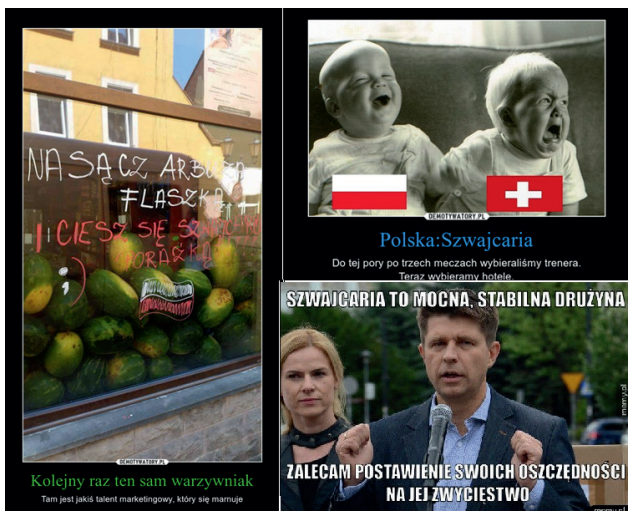

FIGURE 7

Left: Soak a watermelon with booze and enjoy it as the Swiss lose ;) // Once again the same greengrocer // Some marketing whiz, whose talent is being wasted, works there. Right top: Poland: Switzerland // Before, after three matches, we were choosing a coach. Now we are choosing hotels. Right bottom: Switzerland is a strong, stable team. I recommend betting your savings on its victory

Swiss defeat, this meme also invokes (1) the unrealised Polish plan to change the coach to someone who could lead the team to success, and (2) the hotel booking plans that became necessary because of the team's further participation in the championship (when they were successful). The third item alludes to the Swiss team's defeat, but the target of the meme is actually the Polish politician, Ryszard Petru, who is presented in the picture as sharing what is quite clearly bad advice (given the fact that the Swiss team lost the match). This fabricated utterance echoes the fact that Petru had encouraged Poles to take out mortgages in Swiss Francs. Whether or not this advice influenced their actions, many Poles did indeed take out mortgages in Swiss Francs as the currency exchange rate was very low at that time. However, since 2008, the Swiss currency has doubled in value, leading to increasing debts for mortgage holders. This fact is another salient category in the Polish dataset, as shown in the following section.

\subsubsection{The Strong Swiss Franc Debacle}

This category may be tangential to Switzerland per se. It is merely inspired by the steady increase in the value of the Swiss Franc since 2008 (after the Swiss National Bank fixed the Franc to the Euro (1.2:1) in 2011, defending the exchange rate with interventions, which were then removed in 2015 , thus leading to a sharp drop in the exchange rate) and the problems experienced by many Poles as a consequence of this. However, this category deserves to be addressed, given its prevalence in the Polish subcorpus. The meme in Figure 8 relies on a frequently deployed memetic pattern: a proverbial middle-aged Polish couple, Grażyna (woman) and Janusz (man), are represented as long-nosed monkeys. Janusz and Grażyna typify the crude side of Polish society and its vices, some of which are manifest in the meme in Figure 8, which presents 


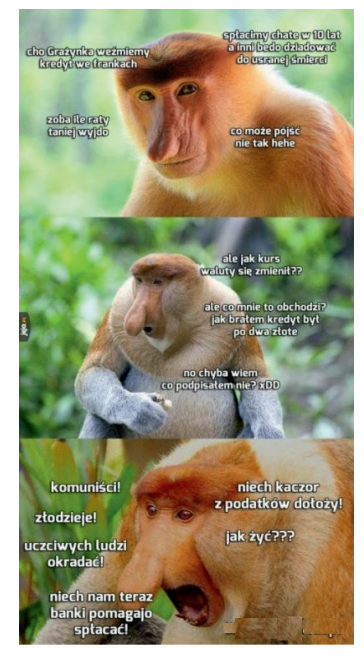

FIGURE 8

The thoughtful face: come on Grażynka, let's take a loan in francs // check out how much cheaper this // we will pay off our house in 10 years and others will be fucked paying till they die // what can go wrong hehe.

The surprised face: but how did the exchange rate change?? // but what do I care? when I took the loan it was two zlotys // I think I know what I signed, right? xDD.

The indignant face: Communists! // thieves! // robbing honest people! // let the banks help us pay it back now! // may "kaczor" [the moniker of the leader of the ruling party] chip in with tax money! // how to live???

proboscis monkeys with different facial expressions along with Janusz's utterances (in non-standard Polish) addressed to his wife. While referring to the consequences of the unfavourable exchange rate of the Swiss Franc, this meme targets some of the stereotypical vices of some members of Polish society: their cunning nature and malediction, their blind stubbornness and irritability, and their propensity for hurling abuse and making extortionate demands that the country should pay off their debts.

\subsection{Swiss Memes about Switzerland}

The Swiss subcorpus contains five cultural scripts relating to the insider perspective.

\subsubsection{Weather}

The most prolific topic in the Swiss-perspective subcorpus is the weather in Switzerland. Memes in this category broadly fall into two types: changeable weather and disappointing summers. The first type presents the weather as unpredictable by juxtaposing two pictures of extreme weather situations and combining them with captions about Switzerland and particular moments in time. The top left example, 'Spring in Switzerland', consists of three parts: (1) At 14:00, a person is reading in a park and enjoying the good weather; (2) at 18:0o, people are walking with umbrellas in the pouring rain; and (3) comedy actor Will Ferrell with an angry facial expression is combined with the message 


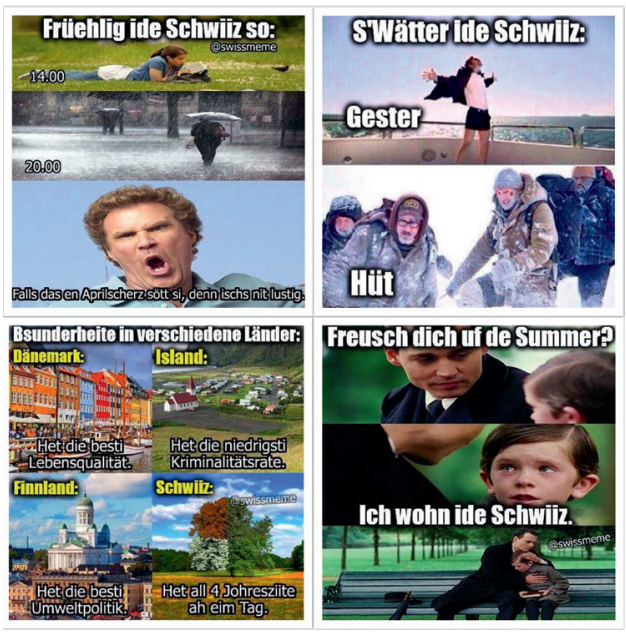

FIGURE 9

Top left: Spring in Switzerland is like: // 14.00 // 20.00 // If this is an April Fool's Day joke, it's not funny.

Top right: The weather in Switzerland: // Yesterday // Today

Bottom left: Particularities in different countries: // Denmark: // Has the best quality of life // Iceland: // Has the lowest crime rate. // Finland: // Has the best environmental policy. // Switzerland: // Has all 4 seasons in one day. Bottom right: Are you looking forward to summer? // I live in Switzerland

'it's not funny', presumably in an attempt to communicate the meme creator's displeasure with the Swiss spring weather. Similarly, the top right example combines a hot weather scene on a yacht with a film still depicting extreme cold and snow. This juxtaposition is then mapped to the timespan from yesterday to today, thus suggesting that seasons in Switzerland change from one day to the next. While most weather memes are not explicitly comparative and only refer to the weather in Switzerland, the example on the bottom left illustrates that some memes also contrast Swiss weather with that experienced in other European countries. In this example, the best qualities of three European countries are named and illustrated, whereas Switzerland is again associated with changeable weather.

The brevity of the Swiss seasons is the main focus of the second type of weather meme, as illustrated in the bottom right example in Figure 9. In this three-part meme (based on stills from the film Finding Neverland), which depicts the poor weather experienced during Swiss summers, (1) a man (Johnny Depp) is asking a young boy (Freddie Highmore) whether he is looking forward to summer; (2) the boy with teary eyes is captioned as saying he lives in Switzerland; and (3) the man hugs the boy to console him. (1) and (2) hyperbolically communicate a message about disappointing Swiss summers. (3) implicates that the man understands the uttered sentiment and, at the same time, appeals to the users' common experience of life in Switzerland, that is, All of us who live in Switzerland know how bad the summers are here'. 

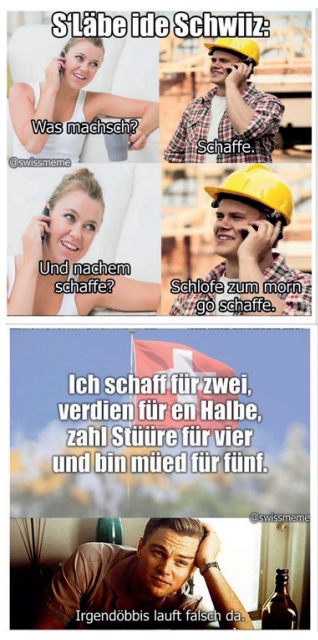

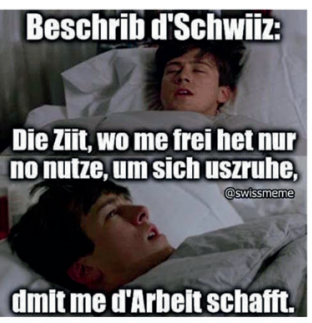

Arzt: "Sie milend die Medizin jede Tag ineh"

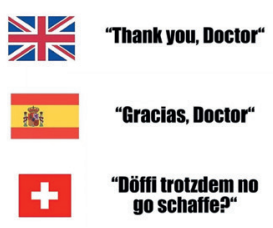

FIGURE 10

Top left: Life in Switzerland: // What are you doing? // Working. // And after work? // Sleeping in order to go to work tomorrow.

Top right: Describe Switzerland: // Using your time off work solely to rest, // in order to get your work done.

Bottom left: I work for two, earn money for a half, pay taxes for four and am tired for five. // Something is going wrong there.

Bottom right: Doctor: "You have to take this medicine every day" // [English]

"Thank you, Doctor" // [Spanish]

"Thank you, Doctor" // [Swiss German]

"May I go to work anyway?"

\subsubsection{A Puritan Work Ethic}

A different type of Swiss-perspective meme focuses on the importance that the Swiss place on work, which eclipses other aspects of life in line with puritan ideology. The examples in Figure 10 suggest that Swiss people value work above everything else: they only sleep and use their leisure time to increase their own work productivity (top left and right). Although they work hard, some Swiss people have small incomes but have to pay a lot of taxes (bottom left), and even when the Swiss are ill, they cannot wait to start working again, in contrast to other nations (bottom right). In these memes, the pictorial resources employed by the memes are numerous. They include flags to represent Switzerland and other countries and intertextual references to films to communicate an emotional stance - the weary faces of Leonardo DiCaprio (bottom left) and Alan Ruck from the film Ferris Bueller's Day Off (top right). In all cases, the pictures are mere illustrations, whereas the work - life imbalance in Switzerland is problematised in the captions.

\subsubsection{Expensive Cinema Snacks}

Another cultural script that surfaces in the Swiss-perspective memes is that of the extortionate price of snacks and beverages in Swiss cinemas. Memes in this group represent particular snack and beverage prices realistically - for instance, 6o CHF for two tickets and some snacks (top right) - or hyperbolically, when it is suggested that a mortgage is required to pay for snacks (bottom left), when prices are compared to gold and diamonds (bottom right) or when 


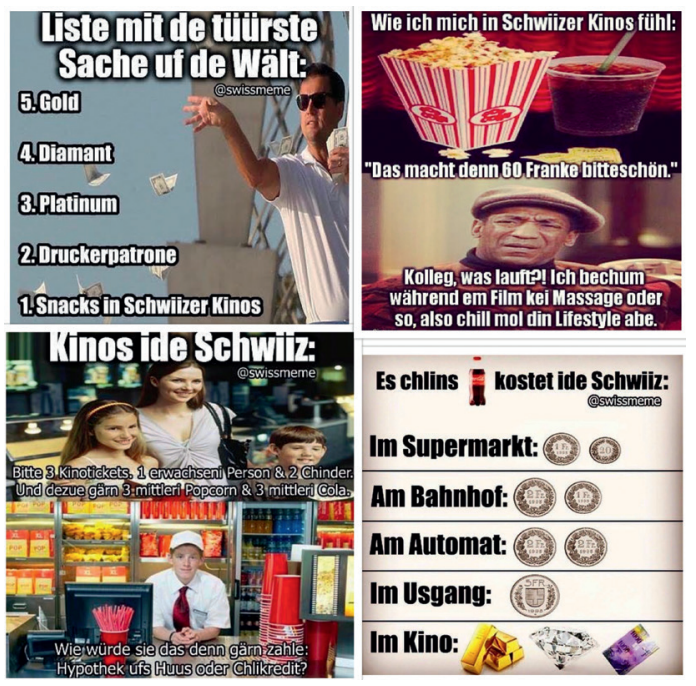

FIGURE 11

Top left: List with the most expensive things in the world: // 5. Gold // 4. Diamond // 3. Platinum // 2. Printer ink cartridges // 1. Snacks in Swiss cinemas

Top right: How I feel in Swiss cinemas: // "That will be 6 o francs, please." // Mate, what's up?! I am not getting a massage during the film or anything like that, so chill down your lifestyle.

Bottom left: Cinemas in Switzerland: // Three tickets please, one adult and two children. And also three medium popcorn and three medium Colas. // How would you like to pay for that: mortgage on your house or consumer loan?

Bottom right: The cost of a small Cola in Switzerland: // At the supermarket: CHF 1.20 // At the train station: CHF 3.- // From a vending machine: CHF 4.- // At the club: CHF 5.- // At the cinema: [pictures of gold bars, a diamond and a CHF 1000.- note]

snacks at the cinema are identified as the world's most expensive commodity (top left).

\subsubsection{Bünzli}

Swiss people are also presented as pedantic and small-minded, as well as having a sense of orderliness that extends not only to themselves but also to others. In Swiss German, a person possessing these characteristics is commonly 
referred to as a 'Bünzli'. A good English explication of the term 'Bünzli' is found on englishforum.ch, where a user defines it as follows:

Bünzlis are people who play by the rules but also wants (sic) to make sure that others, specifically their neighbors also do! A Bünzli person typically has many garden gnomes and is always watching from behind their lace curtains. They will gossip and speculate and report any perceived wrong doing (sic) to the Gemeinde or Police. Extreme examples would be someone going through your rubbish and reporting you for not recycling glass or paper or perhaps complaining about flushing toilets at 22:01 in an apprtment block (sic).

https://www.englishforum.ch/language-corner/61477-b-nzli.html

The example on the top left-hand side of Figure 12 shows a man and woman sitting on a sofa, both of whom are visibly gesturing and engaging in conversation. He asks if she minded (without specifying what he is referring to), while she responds that it is a matter of principle. In this case, and in several other memes in this category, the text presents the personal perception of an offence having been committed and an overreaction to this offence, which is triggered by the Swiss sense of duty along the lines of: 'I do not mind but I complain out of principle' (top left); 'I have to call the police about the noise, even if that noise is piano music that I find enjoyable' (top right); and 'I call the police to complain about the neighbours' loud music rather than asking the neighbours directly about it' (bottom right). Finally, the bottom left example shows a milk carton that has been labelled with the name 'Jessi'. This meme makes fun of the practice of food labelling (which is a common occurrence in large Swiss offices), identifying this action as being typical of Switzerland ('You know you are in a Swiss person's home, when the food in the fridge is labelled'). Extending this practice to a private home, the meme uses hyperbole to emphasise this overly developed sense of orderliness that complies with the Bünzli stereotype.

\subsubsection{Swiss Sophistication versus Foreigner Unsophistication}

While the examples in Section 4.2.4 focused on Swiss behaviours that are positive in moderation but are evaluated negatively when they are taken to extremes, another type of Swiss-perspective meme concerns Swiss behaviours that are presented as positive when compared with the behaviours displayed by foreigners living in Switzerland. Formally, regardless of the point of comparison, these memes are made up of two parts, with each one comprising 


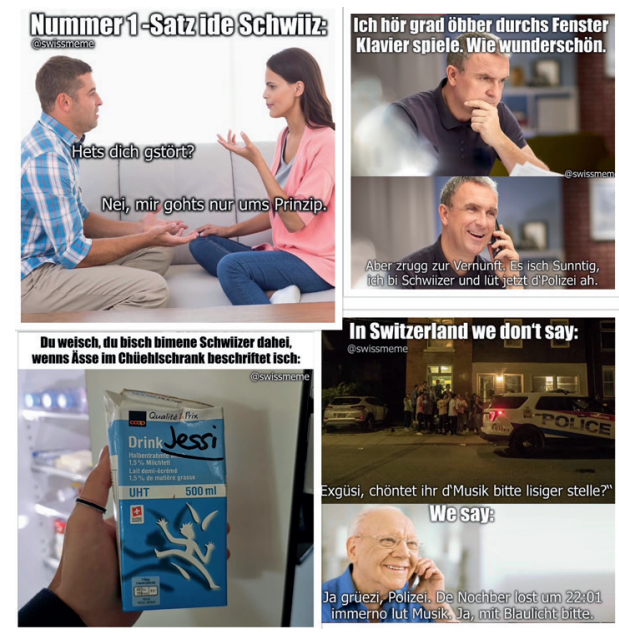

FIGURE 12

Top left: Number 1 sentence in Switzerland: //

Did you mind? // No, for me it's just a matter of principle.

Top right: I can hear somebody play the piano through the window. How wonderfully beautiful. // But back to reason. It is Sunday, I am Swiss and I am calling the police now.

Bottom left: You know you are at a Swiss person's home, when the food in the fridge is labelled: Bottom right: [English] In Switzerland we don't say: // Excuse me, could you please lower the volume of your music? // [English] We say: // Good day, police. The neighbour is still listening to loud music at 22:01. Yes, with flashing blue lights, please.

an image and the wording 'The Swiss:' juxtaposed against 'Foreigners:.' In the top left example in Figure 13, both the Swiss and foreigners ask passengers in the back of their cars to fasten their seatbelts, but do so for very different reasons: the Swiss are concerned about the well-being of other people, while foreigners are more worried about the financial consequences they themselves might suffer. The other memes address topics such as home security (the Swiss have professional alarm systems, whereas foreigners leave their lights on to deter burglars, top right), winter sports (the Swiss know how to ski or snowboard, whereas foreigners merely sledge, bottom left) and culinary skills (the Swiss bake homemade cakes, whereas foreigners buy ready-made products, bottom right). 


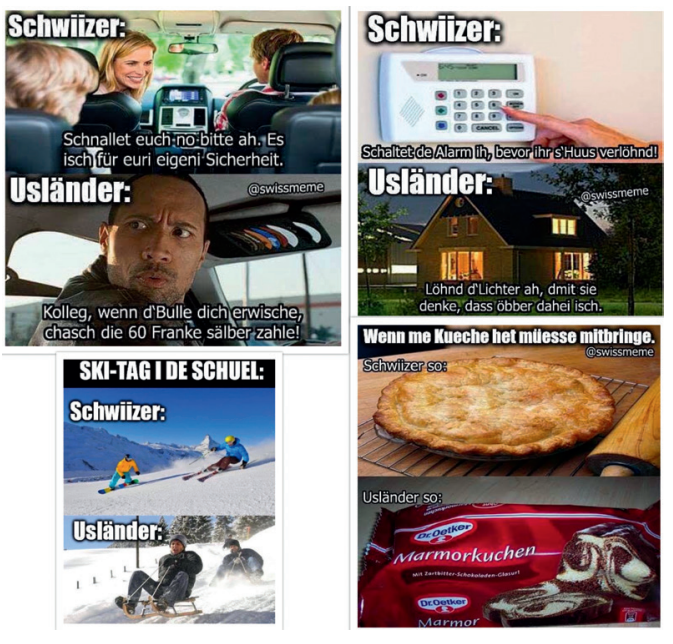

FIGURE 13

Top left: The Swiss: // Fasten your seatbelts please. It is for your own safety. // Foreigners: // Mate, if the cops catch you, you'll pay the 60 CHF yourself!

Top right: The Swiss: // Turn on the alarm system, before you leave the house! // Foreigners: Leave the lights on so they think someone is home.

Bottom left: Skiing day at school: // The Swiss: // Foreigners:

Bottom right: Whenever one had to bring a cake. // The Swiss like: // Foreigners like:

\subsection{International Memes about Switzerland}

We approach the third subcorpus of international memes, which we collected from the website me.me by bearing in mind the results obtained from the Polish and Swiss subcorpora. By doing so, identify four salient cultural scripts.

\subsubsection{Neutrality during Wartime}

As in the case of the Polish memes, Switzerland's neutrality during wartime and, in particular, during the two World Wars - is a topic which is frequently referenced in the international subcorpus. Figure 14 provides four examples, two of which have previously been discussed on the basis of their Polish translations (top left and right). Here, as is the case with the majority of international memes, English captions are provided in order to relate the pictures to the topic of neutrality. A common pattern in these memes involves the depiction of a quarrel between two or more parties, while another party stands nearby, either oblivious to, or not participating in, the ongoing fight (bottom right), but these memes also use television (Mr. Bean, top right) or sports (an impartial fan, bottom left) to depict Switzerland as an uninvolved or uninterested bystander. These metaphorical memes often pertain to World War II, but can also extend to World War I (bottom left) or wars in general (bottom right).

\subsubsection{An outside Observer in Europe}

A different set of memes in the international subcorpus also presents Switzerland as an observer, not in terms of the neutral stance it adopts during wartime, but rather its outsider position in Europe. Figure 15 portrays a meme 


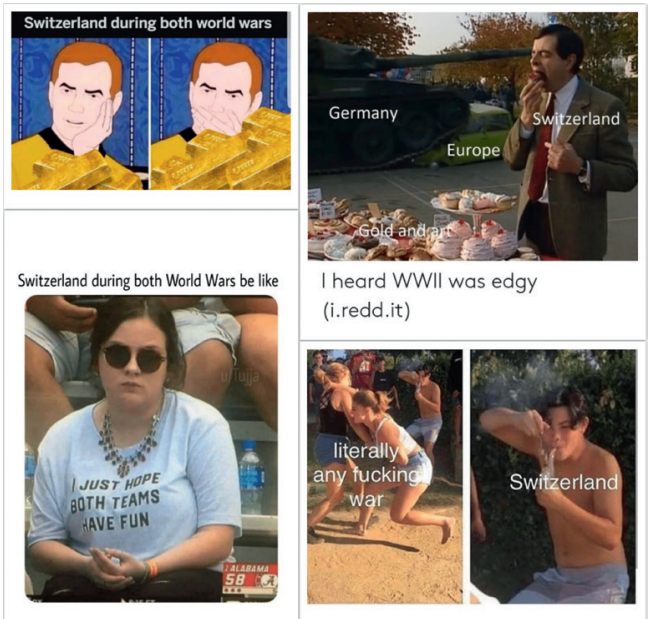

FIGURE 14

(left) in which Germany asks Switzerland whether it wants to join the European Union, an enquiry which Switzerland blocks each time with a simple negative answer 'Nein' . Only in the last part of the meme, when Germany suggests going back to work, does the Swiss ball answer in the affirmative. The importance of work in Switzerland, which serves as a cultural script in the Swiss-perspective corpus, reappears here, but this time the main aim is to present Switzerland as a loner disconnected from the rest of the European community. Similarly, in the meme deploying the popular tuxedowearing Winnie The Pooh template, the famous bear looks smug about the fact that Switzerland is not part of the EU and, therefore, does not face the consequences of the legal acts imposed by the EU, such as Article 13, the EU copyright directive. The meme at the bottom of Figure 15 presents a verbal argument between Germany and Britain, which Switzerland decides to join as a spectator, the wording of which is a screenshot of an online computer game. The example on the right, which also highlights Switzerland's isolation by using an intertextual reference to Disney's animated film The Lion King, is one of the very few international memes that feature Swiss German. While English is the main language used in the captions accompanying the images, the last example assembles Swiss German words (which are not necessarily understood by the international audience). Interestingly, the word 'Chuchichäschtli' - spoken by the hyena and repeated below the image by the person posting the meme, is often used jokingly as a pronunciation test by German-speaking Swiss people for foreign language or (non-Swiss) German speakers. 


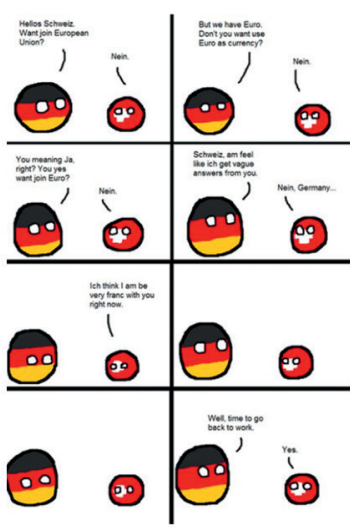

is clasic [Switzerlandball] $\wedge \wedge$
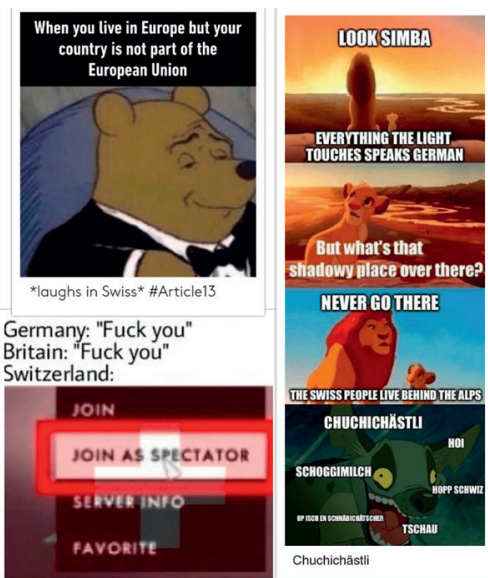

FIGURE 15

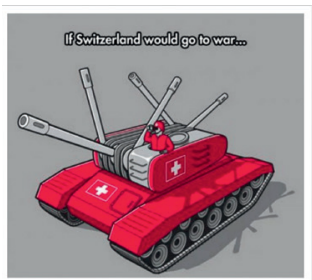

If Switzerland would ever go to war. https://t.co/rTOAK3wpoE

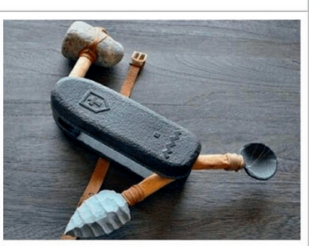

Stone Age In Switzerland.

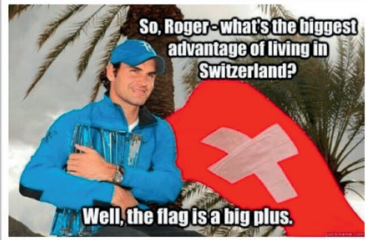

Just a giant plus

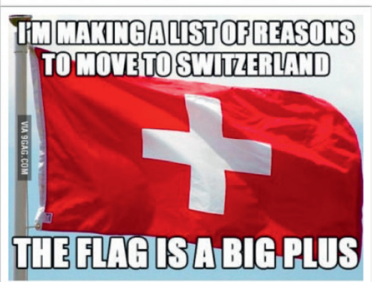

It is, it really is

FIGURE 16

\subsubsection{Symbols}

International memes about Switzerland also employ Swiss symbols in their construction of humour (see Figure 16). For instance, an image of a Swiss army knife is combined with that of a tank, thus reiterating the topic of Switzerland's role during wartime (top left) with a stone-age tool (bottom left). Each of these recontextualised versions of the iconic pocket knife demonstrates that it is an inherent part of Swiss culture. The second group of memes in this category consists of different versions of the same joke. The focus is on the resemblance between the Swiss flag and the plus sign, and could be regarded as a visual 
pun (e.g. Abed, 1994) that involves the cross and a plus sign. This visual pun translates into a verbal pun (based on the polysemy of the word 'plus'). This is illustrated with the items on the right-hand side of Figure 16. While the top right example uses an interview with Swiss tennis player Roger Federer as the context for the joke, the bottom right meme presents the mentioned flag/plus sign as a possible reason for someone moving to Switzerland.

\subsubsection{Affluence and Financial Heaven}

The script of Switzerland's affluence and its status as a financial heaven that was found in the Polish subcorpus also appears in the international memes. As Figure 17 illustrates, one memetic pattern involves the assembling of stereotypes for different countries, including Switzerland. The example on the left, captioned 'Countries Defined By One Sentence', shows the flags of six different countries and combines each image with one sentence. The caption associated with Switzerland is 'Sure, we'll take your money'. The meme in the middle of Figure 17 is a collage of nine 'Meanwhile In' memes, with each country being associated with a stereotypical image. The picture associated with Switzerland shows a vast collection of gold bars. Another example (on the right-hand side of Figure 17) is taken from the Zlatan meme cycle, which - not unlike Chuck Norris jokes previously - is based on exaggerations of footballer Zlatan Ibrahimovic's faculties, knowledge and importance for world events. Here, the Swiss institution is used as a proverbial symbol of affluence that serves to emphasise Ibrahimovic's wealth.

\section{5}

\section{Discussion and Conclusions}

The goal of this qualitative study has been to compare contemporary nation memes relating to Switzerland from the perspective of Polish, Swiss and international social media communities. All the memes in our corpus - namely, three subcorpora taken from Polish, Swiss and international websites which are aimed at their respective audiences - make some reference to Switzerland, albeit from different vantage points. These perspectives have been broadly categorised as either outsider or insider, and are markedly different in nature. In our analysis of the prevailing cultural scripts that underlie what we have termed 'nation memes', we have presented a range of topics, properties and behaviours that are associated with Switzerland and the Swiss people. The scripts found in the insider perspective memes can be categorised as the following: changeable weather in tandem with short summers, a puritan work ethic, expensive cinema snacks, Bünzli, and Swiss sophistication compared 


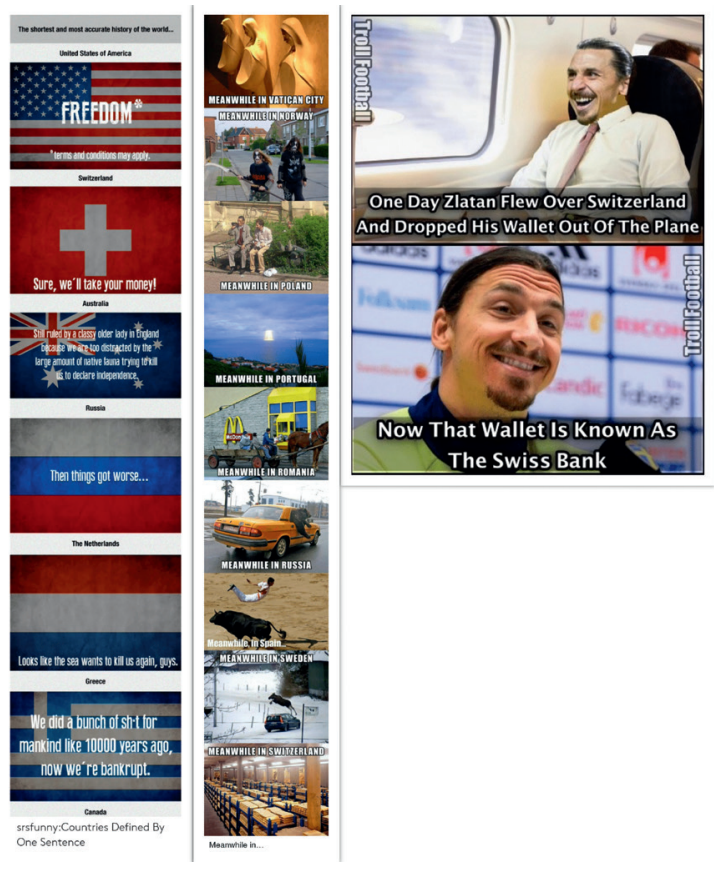

FIGURE 17

to foreigner unsophistication. These scripts are markedly different from those found in the outsider perspective memes, with three common areas being found in the Polish and international memes, namely Switzerland's neutrality, affluence and symbols. The topics found only in the Polish memescape are unusual legal acts, the football match between Switzerland and Poland, and the strong Swiss Franc debacle, with the latter two being intrinsically connected with Polish cultural scripts and, hence, the insider perspective of Poles.

This last category is concerned with digital items that report, whether truthfully or not, unusual legal acts and their consequences. Being a source of cognitive surprise (Forabosco, 1992, 2008; Martin, 2007), these acts constitute sources of humour per se. In some cases, claims that might appear surprising from an outsider perspective may be obvious and non-salient to Swiss residents. In other cases, the described legal acts or facts, even if illustrated with visual material, may well be urban myths that are not necessarily grounded in reliable evidence. It may well be that Switzerland generally represents a place which is sufficiently distant from the website users so that claims about laws and customs cannot be identified as having been fabricated by the meme creators. While too few exist to be included in our presentation of the main meme categories, similar memes which refer to unusual legal acts and 
provide unusual factoids about Switzerland also appear in the international subcorpus.

Both Polish and international humour websites have an abundance of memes which are centred on innocuous visual play or wordplay, such as puns, or metaphorical representations which refer to well-known Swiss symbols, such as the army knife or the country's flag. These symbols are sometimes positioned in larger cultural contexts and employ humorous mechanisms beyond rather simple puns inspired by widely available cultural scripts.

The cultural script of political neutrality, coupled with profit-making, particularly during the two World Wars, is also widespread on both the Polish websites and the international website me.me. Several plausible reasons for the absence of references from Swiss memes to these problematic aspects of Swiss history spring to mind. The simplest explanation is perhaps that the topic lacks any immediate relevance to everyday life, to which most Swiss memes appear to be orientated. However, the fact that neutrality memes are frequently found in outsider memes illustrates the humorous potential that such references to problematic - and well-known - aspects of Swiss history and politics have for international (as opposed to Swiss) meme creators. This script seems to make Switzerland/the Swiss an easy target of humour, with very few alternative vices (to be made fun of) being so widely available. The marked presence of the neutrality script in the Polish data may simply be a consequence of their presence on the international memescape, from where they are often reposted without the creativity that meme formation normally presupposes. Based on the 'something old, something new' policy, humorous digital items are often judged according to their funniness and their novelty/creativity (Vásquez, 2019; Dynel and Poppi, 2019, 2020a). This norm does not appear to hold for the copied memes (concerning not only neutrality but also affluence and symbols) on Polish websites, even though merely changing the code and then reposting is often metapragmatically frowned upon whenever it is detected.

The proverbial Swiss affluence and the financial heaven that Switzerland offers its residents is another cultural script limited to the outsider perspective, being prevalent on Polish humour hubs and the website me.me. Polish and international memes use Switzerland metonymically as a generic, stereotypical representation of wealth that eclipses the wealth of other countries and offers Swiss people financial incentives, which are the envy of Poles. At the same time, Polish meme creators tend to portray themselves in a subservient financial position, sometimes in the context of their everyday experiences (similar to the Swiss perspective on cinema expenses), which they (implicitly or explicitly) juxtapose with the (alleged) corresponding daily experiences of the Swiss. 
In a similar vein, albeit not based on first-hand experience, Polish memes relating to the football match between Switzerland and Poland and the consequences of the Swiss Franc debacle offer an insider Polish perspective on home affairs. Although they invoke scripts concerning Switzerland as their point of departure, these memes appear to focus primarily on Polish cultural scripts concerning the poor performance of the football team and large mortgages. As a result, these memes - which are available to users familiar with the Polish socio-political context - are specific to the Polish memescape.

In turn, experience-based cultural scripts unique to Swiss-perspective memes include changeable weather and short summers, the uneven lifework balance, as well as extortionate snack and beverage prices at the cinema. These three scripts reflect the contemporary daily life experiences of the Swiss community that lives and works in Switzerland. The one category of Swiss-perspective memes most similar to outsider memes about wealth is that of expensive snacks at the cinema. However, Swiss money-related memes are not concerned with the generic welfare of the country; instead, these memes are linked to a common leisure activity and the high prices that customers have to pay when going to the cinema. All three types of the Swissperspective memes describe communal experiences, specifically hardships, that are not only shared but also positioned as being typical of the national culture. A full appreciation of these Swiss-perspective memes requires inside knowledge that only those with first-hand experience of life in this country can possess.

Other topics recurrent in the Swiss subcorpus - namely, Bünzli and Swiss sophistication compared to the properties and behaviours of foreigners - are not necessarily directly linked to everyday existence per se, but they are also presented in memes relating to daily experiences such as driving, phone calls at work or conversations with friends. Both these categories of memes are centred on common stereotypes that the Swiss have about themselves. Bünzli memes are based on the negative stereotype of fussiness and small-mindedness. On the other hand, the Swiss sophistication memes feature stereotypical but positive Swiss behaviours that are in contrast with the behaviours of foreigners, with the latter thus being portrayed as less favourable.

It should be emphasised that the Swiss or Switzerland are not always the targets of humour (cf. Davies, 2002) in our corpus of nation memes, and there can be other targets or none at all. Typically, this is the case with Swiss symbol memes, which offer benign humour about the artefacts associated with the country and are devoid of any evident deprecation, as much humour can be (see Martin, 2007). Some targets can also be non-human, as is the case in outsider memes relating to unusual legal acts or insider weather memes. 
In contrast, memes about Switzerland's neutrality and the Swiss football team appear to metonymically take the entire nation to be the target of humorous disparagement, thereby granting others a sense of superiority (see e.g. Ferguson and Ford, 2008; Martin and Ford, 2018). Similarly, memes which contrast Swiss merits with the activities and principles of foreigners humorously communicate Swiss superiority, either from the Swiss perspective or more likely, given the unmarked nature of Swiss behaviours as viewed by Swiss receivers - from the perspective of the 'foreigners', i.e. residents from another cultural background. In either case, meme creators and receivers should not have any negative dispositions towards, or bear a grudge against, the target. This also ties in with the argument that 'playing' at being aggressive (as opposed to being genuinely aggressive), which is central to at least some forms of humour, does not denote genuine hostility (Davies, 1990, 2002; see also Dynel and Poppi, 2020a for a discussion). There is very little evidence that meme creators or the communities at large passionately care about, for instance, the neutrality of Switzerland during wartime, but yet there are many examples which demonstrate that users keep finding new ways to visualise a battle between opponents in the presence of Switzerland, a pattern which has been extensively employed in previous memes. In these cases, it would appear that the target of the meme is quite arbitrary and is an excuse for creative (Vásquez, 2019) self-expression (leaving the Polish scavenging tendencies aside). Moreover, neutrality memes can tacitly communicate sentiments of envy, given that the neutrality policies appear to have contributed to the country's welfare, pre-empting the problems that other countries face.

Moreover, several meme categories inherently involve the nations presenting themselves as the targets, as is the case with the Bünzli stereotype or the puritan work ethic memes on the Swiss memescape, as well as the self-presentation of Poles as being financially inferior to the Swiss on both a personal level and a public/social level as a country. Both the Polish and Swiss make fun of their national vices and shortcomings, irrespective of whether the meme creators believe that they display the negative features they are depicting, and thus they directly position themselves as the specific target. Memes of this type can be considered to involve self-deprecation. Self-deprecating humour (see Dynel and Poppi, 202ob for an overview and references) humorously highlights one's own vices and shortcomings, which ultimately contributes to a positive self-presentation and a good sense of humour (e.g. Ziv, 1984; Norrick, 1993; Greengross and Miller, 2008). It is worth noting that Polish memes employ Swiss affluence as a yardstick with which specific aspects of Polish life can be measured, notably low income and public welfare services that are in need of improvement. With the exception of 
football-related memes (which deprecate the Swiss team, at times in tandem with the Polish team), the Polish meme creators appear to position their own country as being inferior to Switzerland, and even in these cases their standard pratfalls are addressed.

In an attempt to provide a simplified summary of how Switzerland has been represented in the humorous memes studied in this paper, we conclude that the Switzerland which has been portrayed in the Polish and international memes is seen through the lens of its national symbols, wealth and neutrality during wartime, as well as unusual legal acts. Only rarely do meme creators comment on current issues (as was the case with the football match in 2016), while the vast majority of memes refer to history or timeless, universal issues, which are addressed rather suddenly and unexpectedly. Switzerland is seen either as a benchmark against which a user can measure their own culture or current problems, or as an alien place formed from an amalgamation of a century's worth of world history, economics and current affairs, which Poles and the international community can harmlessly make fun of. In either case, Switzerland is an exoticised and deindividualised place. In contrast, the Switzerland portrayed in Swiss memes is one of hard-working, order-loving people faced with minor everyday problems, such as miserable weather and expensive cinemas. Swiss-perspective memes poke fun at the societal and environmental factors that shape an individual's life in Switzerland - from short summers to long working hours, from strict adherence to all rules to high standards of living that appear to benefit some people more than others.

On the whole, the ways in which Switzerland is represented in nation memes are thus realisations of cultural scripts which are shared by the Swiss or Poles, as well as by the larger international community. It is important to note that these realisations, and the positions that enable these communities to manifest and construct shared mental models of Switzerland, are prototypical examples of the participatory culture of social media in that the creation and reception are situated in the same cultural space in terms of not only national culture but also the community that posts and receives them. Since we understand memes to be intentional communication between posters and receivers, we can also assume that memes are subject to consideration in light of audience design (Clark and Murphy, 1982; see Dynel, 2017 and references therein). Accordingly, memes provide insights not only into the existing attitudes towards Switzerland that are held by meme creators but also into the expectations about experiential and communal common ground (Clark, 1996) with the assumed readership of the memes. Memes can be successfully shared only if attitudes and stereotypes are familiar to/shared by the online communities of Polish, Swiss and international receivers. As witnessed in our study, 
Polish, Swiss and international memescapes present different cultural scripts of both Switzerland and Poland.

Overall, in this paper, we have indicated a number of new areas of research concerning the study of memes across different cultures. This study has accessed data on humour hubs in languages other than English, and has investigated nation memes (which are similar to, but broader than canned jokes about countries) from both insider and outsider perspectives. This has provided insights into prevalent cultural scripts, including stereotypes, which do not necessarily relate solely to the nation under investigation.

\section{Funding Information}

This work was supported by the National Science Centre, Poland (Project number 2018/30/E/HS2/oo644).

\section{Acknowledgement}

Marta Dynel would like to thank Gosia Krawentek for her assistance in the creation of the Polish subcorpus (given her participation in the Project number 2018/30/E/HS2/oo644).

\section{References}

Abed, Farough. 1994. Visual puns as interactive illustrations: Their effects on recognition memory. Metaphor and Symbolic Activity 9(1):45-60.

Al Zidjaly, Najma. 2017. Memes as reasonably hostile laments: A discourse analysis of political dissent in Oman. Discourse \& Society 28(6): 573-594.

Apte, Mahadev L. 1985. Humour and laughter: An anthropological approach. Ithaca: Cornell University Press.

Apte, Mahadev L. 1987 Ethnic humor versus 'sense of humor': an American sociocultural dilemma. American Behavioral Scientist 30(3): 27-41.

Boxman-Shabtai, Lillian, and Limor Shifman. 2015. When ethnic humour goes digital. New Media and Society 17(4):520-539.

Clark, Herbert H. 1996. Using language. Cambridge University Press.

Clark, Herbert H., and Gregory L. Murphy. 1982. Audience design in meaning and reference. In: Jean-Francois Leny, and Walter Kintsch (eds.), Language and Comprehension. Amsterdam: North-Holland Publishing, 287-299. 
Davies, Christie. 199o. Ethnic humor around the world. Bloomington, IN / Indianapolis, IN: Indiana University Press.

Davies, Christie. 2002. The mirth of nations. New Brunswick, NJ: Transaction.

Davies, Christie. 2005. European ethnic scripts and the translation and switching of jokes. Humor 18(2): 147-16o.

Davies, Christie. 2009. Change and continuity in one of Europe's oldest comic ethnic scripts. Humor 12(1): 1-32.

Dawkins, Richard. 1976. The selfish gene. Oxford/New York: Oxford University Press.

de Jongste, Henri. 2016. Mental models and humorous intent. Journal of Pragmatics 95: 107-119.

Dundes, Alan. 1971. A study of ethnic slurs: The Jew and the Polack in the United States. The Journal of American Folklore 84: 186-203.

Dynel, Marta. 2009. Metaphor is a birthday cake: Metaphor as the source of humour. Metaphoric.de 17/2009: 27-48.

Dynel, Marta. 2013. When does irony tickle the hearer? Towards capturing the characteristics of humorous irony. In: Marta Dynel (ed.), Developments in linguistic humour theory. Amsterdam/Philadelphia: John Benjamins, 298-320.

Dynel, Marta. 2016. "I has seen Image Macros!" Advice Animals memes as visual-verbal jokes. International Journal of Communication 10: 66o-688.

Dynel, Marta. 2017. Participation as audience design. In: Christian R. Hoffmann, and Wolfram Bublitz (eds.), Pragmatics of social media. Berlin: Mouton de Gruyter, $61-82$.

Dynel, Marta. 2018. Irony, deception and humour: Seeking the truth about overt and covert untruthfulness. Mouton Series in Pragmatics: Mouton de Gruyter.

Dynel, Marta, and Fabio I. M. Poppi. 2019. Risum teneatis, amici?: The socio-pragmatics of RoastMe humour. Journal of Pragmatics 139: 1-21.

Dynel, Marta, and Fabio I. M. Poppi. 2020a. Quid rides: Targets and referents of RoastMe insults. HUMOR: International Journal of Humour Research. https://doi .org/10.1515/humor-2019-0070.

Dynel, Marta, and Fabio I. M. Poppi. 202ob. Arcana imperii: The power of humorous retorts to insults on Twitter.Journal of Language Aggression and Conflict 8(1): 57-87. https://doi.org/10.1075/jlac.ooo31.dyn.

Ferguson, Mark A., and Thomas E. Ford. 2008. Disparagement humour: A theoretical and empirical review of psychoanalytic, superiority, and social identity theories. Humor 21(3): 283-312.

Forabosco, Giovannantonio. 1992. Cognitive aspects of the humour process: The concept of incongruity. Humor 5(1-2): 45-68.

Forabosco, Giovannantonio. 2008. Is the concept of incongruity still a useful construct for the advancement of humor research? Lodz Papers in Pragmatics 4(1): 45-62. 
Forceville, Charles. 2008. Metaphor in pictures and multimodal representations. In: Raymond W. Gibbs, Jr. (ed.), The Cambridge handbook of metaphor and thought. Cambridge, UK: Cambridge University Press, 462-482.

Forceville, Charles, and Eduardo Urios-Aparisi (eds.). 20o9. Multimodal metaphor. Berlin: Mouton de Gruyter.

Gal, Noam, Limor Shifman, and Zohar Kampf. 2016. "It Gets Better": Internet memes and the construction of collective identity. New Media \& Society 18(8): 1698-1714.

Greengross, Gil, and Geoffrey F. Miller. 2008. Dissing oneself versus dissing rivals: Effects of status, personality, and sex on the short-term and long-term attractiveness of self-deprecating and other-deprecating humor. Evolutionary Psychology 6(3): 393-408.

Hirsch, Galia. 2017. Humor appreciation in the digital era. Lingua 197:123-140.

Huntington, Heidi E. 2015. Pepper spray cop and the American dream: Using synecdoche and metaphor to unlock internet memes' visual political rhetoric. Communication Studies 67(1): 77-93.

Jenkins, Henry, Ravi Purushotma, Margaret Weigel, Katie Clinton, and Alice J. Robinson. 2009. Confronting the challenges of participatory culture: Media education for the 21st century. Cambridge: The MIT Press.

Jiang, Yaqian, and Camilla Vásquez. 2019. Exploring local meaning-making resources: A case study of a popular Chinese internet meme (biaoqingbao). Internet Pragmatics. http://doi.org/10.1075/ip.00042.jia.

Kecskes, Istvan. 2014. Language, culture, and context. In: Farzad Sharifian (ed.), The Routledge handbook of language and culture. New York: Routledge, 113-128.

Knobel, Michele, and Colin Lankshear. 2007. Online memes, affinities, and cultural production. In: Michele Knobel, and Colin Lankshear (eds.), A new literacies sampler. New York: Peter Lang, 199-227.

Kristeva. Julia. 1980. Word, dialogue, and novel. In Leon Roudiez (ed.), Desire in language: A semiotic approach to literature and art (trans. Thomas Gora, Alice Jardine, and Leon Roudiez). New York: Columbia University Press, 64-91.

Kuipers, Giselinde. 2000. The difference between a Surinamese and a Turk: Ethnic jokes and the position of ethnic minorities in the Netherlands. Humor 13(2):141-175.

Martin, Rod. 2007. The psychology of humour. An integrative approach. Burlington: Elsevier.

Martin, Rod, and Thomas Ford. 2018. The psychology of humour. An integrative approach. Burlington: Elsevier.

Messerli, Thomas C., and Yu Di. 2018. Multimodal construction of soccer-related humor on Twitter and Instagram. In: Ridvan Askin, Catherine Diederich, and Aline Bieri (eds.), The aesthetic, poetics, and rhetoric of soccer. London and New York: Routledge, $227-255$. 
Milner, Ryan M. 2013. Pop polyvocality: Internet memes, public participation, and the Occupy Wall Street movement. International Journal of Communication 7: 2357-239o.

Milner, Ryan M. 2016. The world made meme: Public conversations and participatory media. Cambridge, MA: Mit Press.

Nissenbaum, Asaf, and Limor Shifman. 2018. Meme templates as expressive repertoires in a globalizing world: A cross-linguistic study. Journal of Computer-Mediated Communication 23(5): 294-310.

Norrick, Neal. 1989. Intertextuality in humor. Humor 2(2):117-140.

Norrick, Neal. 1993. Conversational joking: Humor in everyday talk. Bloomington, IN: Indiana University Press.

Popescu, Carmen. 2011. Understanding ethnic humour in Romanian jokes. In: Marta Dynel (ed.), The pragmatics of humour across discourse domains. Amsterdam: John Benjamins, 173-19o.

Ross, Andrew S., and Damian J. Rivers. 2017. Digital cultures of political participation: Internet memes and the discursive delegitimization of the 2016 U.S presidential candidates. Discourse, Context and Media 16: 1-11.

Schutz, Charles E. 1989. The sociability of ethnic jokes. Humor 2(2): 165-177.

Sebba-Elran, Tsafi, and Haya Milo. 2016. The struggle over locality in Israeli humoristic memes from the 2014 military conflict in Gaza. Narrative Culture 3(2): 206-230.

Shifman, Limor. 2013. Memes in digital culture. Cambridge, MA: MIT Press.

Shifman, Limor, Hadar Levy, and Mike Thelwall. 2014. Internet jokes: The secret agents of globalization? Journal of Computer Mediated Communication 19(4): 727-743.

Takovski, Aleksandar. 2018. Extending ethnic humour theory: Genuine vs. functional ethnic joke scripts. The European Journal of Humour Research 6(2): 6o-8o.

Tsakona, Villy. 2009. Language and image interaction in cartoons: Towards a multimodal theory of humor. Journal of Pragmatics 41(6): 1171-1188.

van Dijk, Teun A. 2008. Discourse and context: A sociocognitive approach. Cambridge, UK: Cambridge University Press.

Vásquez, Camilla. 2019. Language, creativity and humour online. London: Routledge.

Weaver, Simon. 2011. Jokes, rhetoric and embodied racism: A rhetorical discourse analysis of the logics of racist jokes on the Internet. Ethnicities 11(4): 413-435.

Weaver, Simon, and Piotr Ozieranski. 2015. New European tricksters: Polish jokes in the context of European Union labour migration. International Journal of Cultural Studies 19(5): 577-591.

Wierzbicka, Anna. 2014. Language and cultural scripts. In: Farzad Sharifian (ed.), The Routledge handbook of language and culture. New York: Routledge, 339-356.

Wiggins, Bradley E., and G. Bret Bowers. 2015. Memes as genre: A structurational analysis of the memescape. New Media \& Society 17(11): 1886-19o6. 
Yus, Francisco. 2017. Incongruity-resolution cases in jokes. Lingua 197:103-122.

Yus, Francisco. 2019. Multimodality in memes. A cyberpragmatic approach. In: Patricia Bou-Franch, and Pilar Garcés-Conejos Blitvich (eds.), Analyzing digital discourse: New insights and future directions. Cham: Palgrave Macmillan, 105-131.

Zhang, Leticia Tian, and Daniel Cassany. 2019. Multimodal humor in danmu video comments. Internet Pragmatics. https://doi.org/10.1075/ip.ooo38.zha.

Ziv, Avner. 1984. Personality and sense of humour. New York: Springer. 